\section{Abstract}

8

10

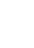

\title{
Experimental investigation on heat transfer of n-pentane spray impingement on piston surface
}

\author{
Zhi-Fu Zhou ${ }^{*}$, Safwan Hanis Mohd Murad², Jia-Meng Tian¹, Joseph Camm², Richard Stone ${ }^{2 *}$
}

${ }^{1}$ State Key Laboratory of Multiphase Flow in Power Engineering, Xi'an Jiaotong University, Xi'an, 710049, China

${ }^{2}$ Department of Engineering Science, University of Oxford, Oxford, OX1 3PJ, UK

*Corresponding author: zfzhou@mail.xjtu.edu.cn;

richard.stone@eng.ox.ac.uk

\begin{abstract}
Fuel spray impingement on piston surfaces is a concern because it can cause particulate exhaust emissions from
\end{abstract} gasoline direct injection (GDI) engine. Transient heat transfer plays an important role that directly influences liquid film evaporation and its lifetime. In this paper, the effects of injection temperature, injection pressure, piston temperature and impact distance on n-pentane spray impingement heat transfer were fully examined. Results showed that increasing the piston temperature could increase the rate of heat transfer with a larger surface temperature reduction and a higher heat flux, which led to a shorter liquid film lifetime on the piston surface. Increasing the fuel injection temperature helped to improve atomization of the fuel spray, reduce the penetration distance and mitigate impact, which in turn led to reduced surface cooling and less liquid film on the piston surface. A decrease in impact distance and an increase in injection pressure both caused an increase in surface temperature reduction and heat flux but a decrease in the liquid film residence time. The dimensionless heat flux in terms of Biot and Fourier numbers presented a high similarity during the rapid cooling stage. A dimensionless correlation was formed to quantify this fast time-varying heat transfer behaviour.

Keywords: transient heat transfer; spray impingement; particulate matter emissions; n-pentane; GDI engines 
The fuel spray impingement on a cylinder/piston surface causes wall wetting, which is a source of several problems for

23 gasoline direct injection (GDI) engines, including deterioration of engine performance, dilution of the lubricating oil and

24 production of a liquid film deposited on the wall surface $[1,2]$. Amongst these, the most important is the formation of a

25 liquid film on the wall surface, which cannot evaporate completely and mix well with air due to the short time between the

26 end of injection and ignition [3, 4]. The fuel rich region near the wall surface, due to liquid film evaporation from the wall

27 surface, causes incomplete combustion and subsequently accounts for a higher level of particulate matter (PM) emissions

28 than from port fuel injection (PFI) engines [5]. Currently, fuel impingement and its consequent wall wetting have been

29 subject to increased attention because of the increasingly stringent emission standards and the environmental and human

30 health concerns. Dynamic heat transfer has been identified as one of the most important processes during the spray-wall

31 interaction, influencing the liquid film formation and evaporation. During the very short time within each engine cycle, the

32 heat transfer process undergoes different regimes from single phase convection to nucleate boiling, and even to the

33 Leidenfrost point, and the unsteady heat flux to the liner/piston wall varies from zero to as high as several MW/m² $[6,7]$.

Although numerical research has been conducted on spray-wall interactions in GDI engines, most of them concern the

spray and its impingement morphology [8-14]. Only a few studies on heat transfer and the wall surface heat flux for GDI

engines have been published. Serras-Pereira et al. $[15,16]$ used a fast-response heat flux sensor to record the heat flux on a

cylinder liner exposed to fuel impingement, and the effect of engine temperature, fuel properties and injection strategies was

investigated. It was found that the heat flux peak due to impingement was greatly related to the fuel injection temperature

and properties, and an injection strategy using split injection was proposed to reduce impingement onto the engine's liner.

Wang et al. [7] used the eroding-type surface thermocouples to measure surface temperature, and later developed a

two-dimensional finite element model to calculate the heat flux. The peak heat flux at certain operating conditions due to

the impingement could be over $1.5 \mathrm{MW} / \mathrm{m}^{2}$. The ignition timing, air-fuel ratio and mixture preparation largely affected the

engine heat flux and heat release. Köpple et al. [5] used eight fast-response thermocouples embedded $0.3 \mu \mathrm{m}$ beneath the

44 piston surface to quantify the temperature drop due to the fuel impingement. Also a parametric study with variables such as 
spray pressure, engine load and speed was conducted. Their results showed that a higher injection pressure resulted in a

larger temperature reduction on the piston surface but with a lower level of particulate number emissions due to less liquid

film being formed. Terrence et al. [17] investigated the liquid film evaporation process on a piston surface using schlieren imaging. It was found that the liquid film did not evaporate until late in the power stroke and the in-cylinder temperature during the later evaporation process was too low to completely oxidize the evaporating fuel, causing much higher HC emissions. Schulz et al. [18] investigated the effect of spray angle, wall temperature and spray pressure on the spray/wall interaction and wall/film phenomena in replicated GDI engine conditions using a high-speed infrared camera. It was found that the temperature at the spray impingement zone decreased heavily due to the transient heat transfer and was sensitive to all test parameters; the wall film mass could be reduced by adjustment of the injection pressure and impact angle. Arcoumanis et al. $[19,20]$ related the spray characteristics of droplet velocity to heat transfer on an impinging surface, developing a Nu-Re-Pr-We correlation for the instantaneous and spatially-resolved spray/wall heat transfer for simulated diesel spray conditions. Moreira et al. [21, 22] also developed an empirical correlation to describe the heat transfer process in a simulated gasoline spray experiment. Hsieh et al. [23] reported that a lower temperature surface led to faster growth of the deposit area in a spray burner. Montanaro et al. [24] found that at first the increase of impinging surface temperature could decrease the spread of the liquid film but further increases beyond the Leidenfrost point caused an increased spread. In addition to the above mentioned injection temperature, pressure, fuel property and injection strategy, there are some other factors influencing heat transfer due to spray impingement. For example, the ambient turbulence also has a strong influence on the spray characteristics and heat transfer [25].

As mentioned above, the heat transfer due to fuel spray impingement on a wall surface is a complicated and transient process, and affects the liquid film formation, morphological behaviour and evaporation, all of which in turn influence the engine performance and particulate emissions significantly. The objective of this work is to advance the understanding of the spray-wall interaction phenomena and the emphasis is to quantify the heat transfer behaviour on the impinging surface by recording the surface temperature and calculating the heat flux under different conditions with the fast-response PRT technique and a 2D heat flux estimation method. 
Fig. 1 presents the schematic of experimental rig. The injector is a modified six-hole nozzle spray injector for the

71 Jaguar Land Rover AJ133 engine, further details of which can be found in [26, 27]. Only one hole of the injector is used to

inject fuel (n-pentane), as the other five holes are sealed in these experiments. The injector is appropriately positioned on

73

injector temperature can be controlled by a Labview system using PID temperature feedback control. The spray chamber used a full length optical cylinder liner with inner diameter of $89 \mathrm{~mm}$, and is open to the atmosphere at the top with air drawn from the bottom by an extraction and dilution system. A surrogate piston made of copper is installed within the spray chamber and is drilled with seven holes for heater elements insertions. The piston is insulated except for the top surface which is exposed to the fuel impact. The copper piston is heated to controlled temperatures with fuel being sprayed onto the surface under the control of another Labview system. The fuel is pressurized through a stepped-piston intensifier using compressed nitrogen. The maximum pressure provided by this pump can reach 300 bar. Pulses are sent to a Bosch injector driver from the LabVIEW system with fully configurable injection duration and injection period. Much more detailed information about this spray rig can be seen in [28].

A Photron Fastcam 1024 PCI camera is used to visualize the spray. The spray images are taken at 4500 frames per second with illumination for Mie scattering using an f/1.2 lens and a 100 W LED array. The exposure is set to $3.30 \mu$ s to capture as much transient detail of the spray as possible.

A fast-response thin film Platinum Resistance Thermometer, (with a thickness of only $\sim 0.5 \mu \mathrm{m}$ ) is used to measure the surface temperature change when fuel impingement occurs. There is an array of 8 PRTs fabricated onto a strip of thin flexible $50 \mu \mathrm{m}$ polyimide insulating layer (Upilex) that is attached to the top surface of the surrogate piston, which has a diameter of $50 \mathrm{~mm}$. The eight measurement points are arranged across the centre of piston surface. Before the experiment, careful calibration for the eight PRTs is done to obtain the correlations between the temperature and voltage acquired by the NI-DAQ card. In the whole experimental system, there is a pulse signal controlled by a manual switch that is used to trigger the starts of injector, high speed camera and temperature acquisition simultaneously. According to the PRTs manufacture of 
its temporal resolution was $0.1 \mathrm{~ms}$, limited by the sample rate rather than the sensors.

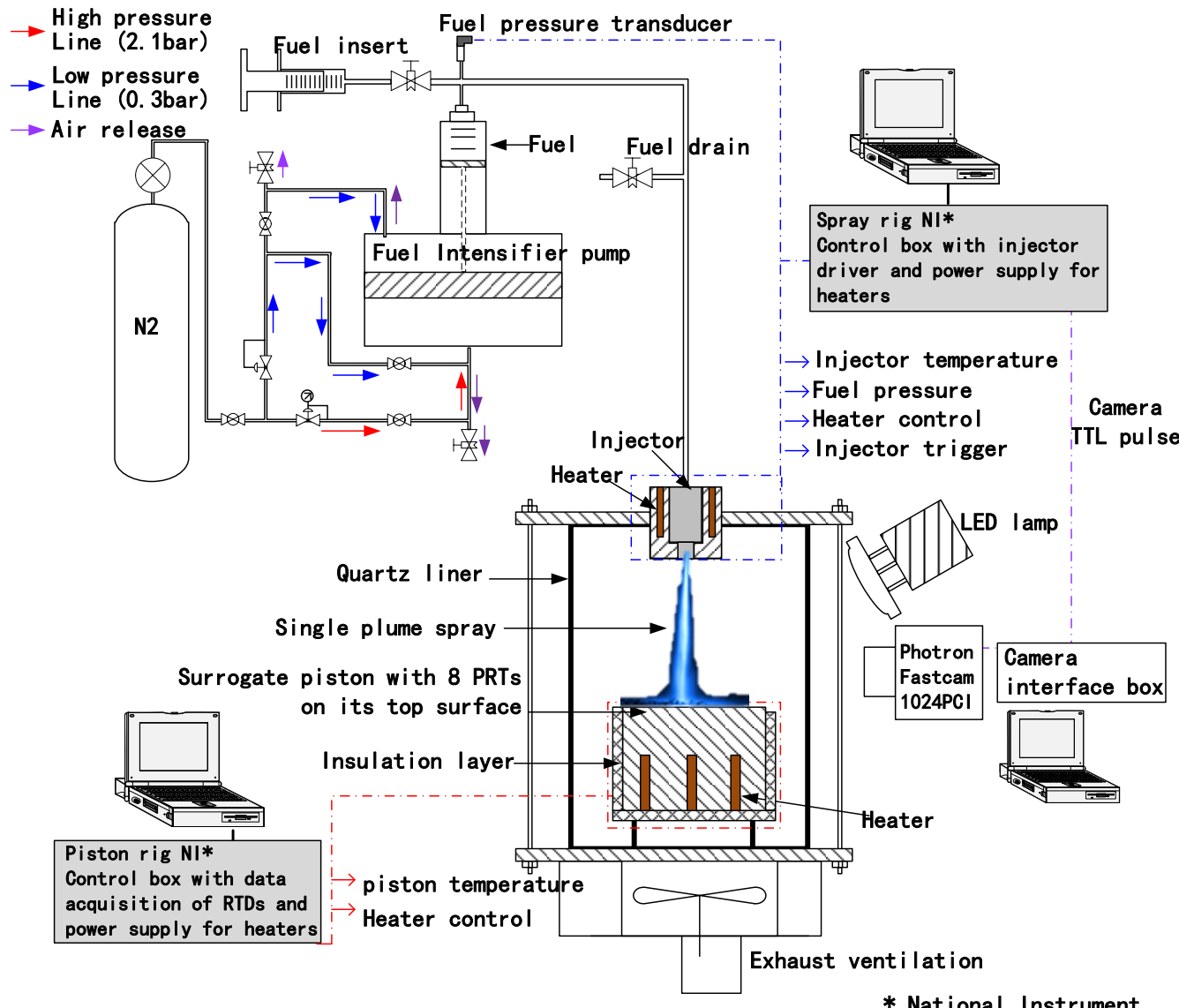

Fig. 1 Schematic of the experimental system

3 Surface transient heat flux calculation

\subsection{Two-dimensional heat transfer model}

Surface heat flux is a key parameter for characterizing heat transfer, however, it is relatively difficult to measure the

time-varying heat flux directly for a transient problem. Alternatively, it can be derived from the measured temperature at a

certain position by solving the inverse heat conduction problems (IHCP). In this study, the surface heat flux is calculated

based on the temperature measured by PRTs on the piston surface. The impingement surface is circular, therefore heat

transfer occurs only along the radial direction on piston surface. Besides, heat transfer inevitably happens towards piston

depth direction. Therefore, a two dimensional heat transfer model should be considered to calculate the heat flux more 
heat flux calculation is shown in Fig. 2, in which the $x$ direction is the radial direction on the piston surface and $y$ direction

is the depth direction of piston. The model is composed by two layers. Layer 1 is an insulating layer $\left(\mathrm{Upilex}, H_{1}=50 \mu \mathrm{m}\right)$

on the top surface of which the thin PRTs are deposited. Eight PRTs are arranged in a line with a spacing of $6.25 \mathrm{~mm}$. The thermal properties of Upilex can be found in Reference [29]. Layer 2 is the copper $\left(H_{2}=20 \mathrm{~mm}\right)$ of the surrogate piston.

The thickness of the PRTs $(0.5 \mu \mathrm{m})$ can be neglected since it is far smaller than those of the two other layers. Thus, the

temperature measured by the PRTs can be directly regarded as the surface temperature of Layer 1 in the heat flux

2D method, the heat flux is assumed to be uniform in one discrete domain (eg. $0 \leq x \leq x_{1}$ ). In this model, heat transfer only

as isothermal.

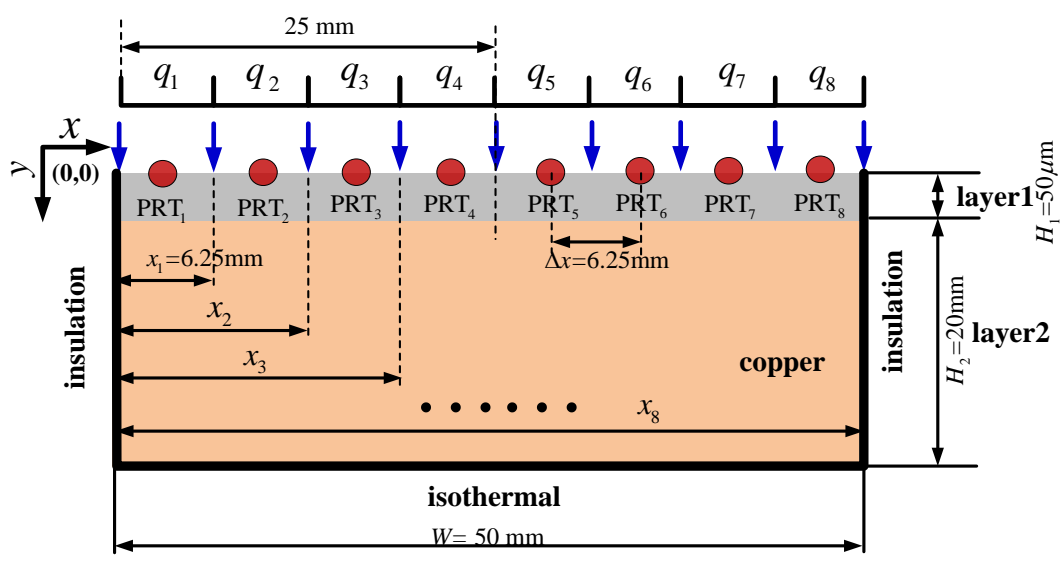

Fig. 2 Geometry model of the two-layer system for solution of the Inverse Heat Conduction problem (IHCP) with the PRTs;

The mathematical description of the direct heat conduction problem shown in Fig. 2 with $j$ heat fluxes and temperature

sensors, and $i$ layers can be written as

$$
\frac{\partial^{2} T_{i}}{\partial x^{2}}+\frac{\partial^{2} T_{i}}{\partial y^{2}}=\frac{1}{\alpha_{i}} \frac{\partial T_{i}}{\partial t} \quad(0 \leq x \leq W, 0 \leq y \leq H),
$$

where $T$ is temperature, $t$ is time, $\alpha$ is the thermal diffusivity coefficient $(\alpha=\lambda / \rho c)$, and $i$ denotes parameters in the $i^{\text {th }}$ layer. 


$$
\begin{gathered}
\frac{\partial T}{\partial x}(0, y, t)=\frac{\partial T}{\partial x}(W, y, t)=\frac{\partial T}{\partial y}(x, H, t)=0, \\
-\lambda \frac{\partial T_{1}}{\partial y}(x, 0, t)=\left\{\begin{array}{c}
q_{1}(t), 0 \leq x \leq x_{1} \\
q_{2}(t), x_{1} \leq x \leq x_{2} \\
\vdots \\
q_{\mathrm{J}}(t), x_{\mathrm{J}-1} \leq x \leq x_{\mathrm{J}}
\end{array}\right. \\
T(x, y, 0)=T_{0} \quad(0 \leq x \leq W, 0 \leq y \leq H) .
\end{gathered}
$$

In the IHCP, unknown heat fluxes are calculated based on the measured temperature by the sensors, which can be described as

$$
T\left(x_{\mathrm{PRT}_{j}}, H_{\mathrm{T}}, t\right)=Y_{j}(t) \quad j=1,2,3 \cdots, \mathrm{J},
$$

where the subscript $\mathrm{PRT}_{j}$ denotes the lateral location of the $j^{\text {th }}$ sensor, $Y_{j}$ is the measured temperature by the PRTs, and $H_{\mathrm{T}}$ is the measurement location in the $y$ direction.

For the multi-layer and 2-D transient inverse heat conduction problem, it is hardly possible to get its exact/analytical solution. Alternatively, we calculate the heat flux through the numerical method.

\subsection{Mathematical description of 2D heat flux calculation}

In the direct heat conduction problem, the temperature distribution can be solved directly by the known surface heat flux based on Eqs. (1)-(4). However, when the surface heat flux is unknown and the temperature at a certain location is measured, it is the IHCP. The IHCP solution is developed based on the minimization of the errors between estimated and measured temperatures. Afterwards, this solution is expressed in a digital filter form. The discrete solution for temperature can be represented as

$$
\mathbf{T}=\mathbf{X q}
$$

where $\mathbf{T}$ is the real temperature matrix, $\mathbf{X}$ is the sensitivity matrix, and $\mathbf{q}$ denotes heat fluxes. $\mathbf{X}$ can be obtained by solving Eqs. (1)-(5) with a unit surface heat flux [30-34] for a given heat transfer model. The sum of the squares of the errors between the estimated and measured temperatures plus first-order regularization, $S$, is

$$
S=(\mathbf{Y}-\mathbf{T})^{\prime}(\mathbf{Y}-\mathbf{T})+\alpha_{t}\left[\mathbf{H}_{\mathbf{t}} \mathbf{q}\right]^{\prime}\left[\mathbf{H}_{\mathbf{t}} \mathbf{q}\right]+\alpha_{s}\left[\mathbf{H}_{\mathrm{s}} \mathbf{q}\right]^{\prime}\left[\mathbf{H}_{\mathrm{s}} \mathbf{q}\right]
$$


where $\mathbf{Y}$ is the measured temperature matrix with a form similar to that of real temperature matrix T. $\alpha_{t}$ and $\alpha_{s}$ are

regularization parameters with respect to temporal and spatial terms, respectively. The superscript ' denotes the transpose of

a matrix. $\mathbf{H}_{\mathrm{t}}$ and $\mathbf{H}_{\mathrm{s}}$ are the temporal and spatial first order regularization matrixes.

Minimizing $S$, the estimated heat flux matrix $\widehat{\mathbf{q}}$ using the entire domain data yields

$$
\hat{\mathbf{q}}=\left[\mathbf{X}^{\prime} \mathbf{X}+\alpha_{t} \mathbf{H}_{\mathbf{t}}^{\prime} \mathbf{H}_{\mathbf{t}}+\alpha_{s} \mathbf{H}_{\mathbf{s}}^{\prime} \mathbf{H}_{\mathbf{s}}\right]^{-1} \mathbf{X}^{\prime} \mathbf{Y}=\mathbf{F Y}
$$

The filter solution indicates that the heat flux at each time step is only related to the temperature from several previous and future time steps, independent from the rest of the temperature data [32]. Therefore, the filter matrix $\mathbf{F}$ can be expressed as

$$
\mathbf{F}=\left[\begin{array}{ccccccc}
\mathbf{f}_{0} & \mathbf{f}_{-1} & \mathbf{f}_{-2} & \cdots & \mathbf{f}_{3-\mathrm{N}} & \mathbf{f}_{2-\mathrm{N}} & \mathbf{f}_{1-\mathrm{N}} \\
\mathbf{f}_{1} & \mathbf{f}_{0} & \mathbf{f}_{-1} & \mathbf{f}_{-2} & \mathbf{f}_{-3} & \cdots & \mathbf{f}_{2-\mathrm{N}} \\
\vdots & \ddots & \ddots & \ddots & \ddots & \ddots & \vdots \\
\mathbf{f}_{\mathrm{m}_{p}} & \mathbf{f}_{\mathrm{m}_{\mathrm{p}}-1} & \cdots & \mathbf{f}_{0} & \cdots & \mathbf{f}_{-\mathrm{m}_{t}+1} & \mathbf{f}_{-\mathrm{m}_{t}} \\
\vdots & \vdots & \vdots & \vdots & \ddots & \vdots & \vdots \\
\mathbf{f}_{\mathrm{N}-2} & \mathbf{f}_{\mathrm{N}-3} & \cdots & \vdots & \mathbf{f}_{1} & \mathbf{f}_{0} & \mathbf{f}_{-1} \\
\mathbf{f}_{\mathrm{N}-1} & \mathbf{f}_{\mathrm{N}-2} & \mathbf{f}_{\mathrm{N}-3} & \cdots & \mathbf{f}_{2} & \mathbf{f}_{1} & \mathbf{f}_{0}
\end{array}\right],
$$

where $N$ is the total time steps, $\mathbf{f}$ denotes $K \times J$ block filter coefficients, $m_{\mathrm{p}}$ and $m_{\mathrm{f}}$ are the numbers of non-negligible filter coefficients before and after the current time step. The values of $\alpha_{t}, \alpha_{s}, m_{\mathrm{p}}$ and $m_{\mathrm{f}}$ can be determined by the optimal comparison criterion that is described in detail in our previous study [33]. In this work, $\alpha_{t}=\alpha_{s}=10^{-9}, m_{\mathrm{p}}=1395, m_{\mathrm{f}}=26$.

Given that most filter coefficients can be disregarded except those of the $\left(m_{\mathrm{p}}+m_{\mathrm{f}}+1\right)$ time step, the solutions for 2D single-layer IHCP can be simplified into a general filter solution as

$$
q_{k}(n)=\sum_{m=1}^{\left(\mathrm{m}_{\mathrm{p}}+\mathrm{m}_{\mathrm{f}}+1\right) \times \mathrm{J}}\left(f_{k, m} Y_{\left(n-\mathrm{m}_{\mathrm{p}}-1\right) \times \mathrm{J}+m}\right),
$$

where $n$ denotes the $n^{\text {th }}$ time step. $f_{k, m}$ denotes the filter coefficient in the $m^{\text {th }}$ column from one row of $\mathbf{F}$ associated with the

$k^{\text {th }}$ unknown heat flux. Details of matrix $\mathbf{T}, \mathbf{X}, \mathbf{Y}, \mathbf{q}, \mathbf{H}_{\mathbf{t}}, \mathbf{H}_{\mathbf{s}}$, and $\mathbf{f}$ can be seen in our recent work [33].

\section{Experimental uncertainty analysis}

The repeatability of the experiment is carefully examined through multi experimental tests. During three measurements

of surface temperature at the same injection conditions, it is noticed that all the three temperature curves are close to each 
points) were less than $1 \mathrm{~K}$. As a result, the heat flux based on the surface temperature data also has good repeatability, little deviation from their average value for each curve during the three experiments (less than $\left.5 \mathrm{~kW} / \mathrm{m}^{2}\right)$. And the time $\left(t_{\max }\right)$

when heat flux reaches its peak value takes place at the same time.

As for the experimental error, the PRTs have been calibrated against an ASTM mercury-in-glass distillation

thermometer with a resolution of $0.2 \mathrm{~K}$; such thermometers are typically accurate to better than $\pm 0.1 \mathrm{~K}$. Any drift in the

Wheatstone bridge balance will not be important as heat flux is derived from the rate of change of temperature. In the

following results, we do not show the error bars because of too many points for all the curves and the quite small

uncertainty.

\section{Results and discussions}

\subsection{Spray images}

For the $2 \mathrm{~ms}$ duration fuel spray captured by the high-speed camera at $4500 \mathrm{fps}$, then about ten spray images can be

recorded. The spray images are time resolved, for which only the images reaching the maximum spray intensity and width

are presented in this section. Fig. 3 presents images of a spray plume and its impingement on the piston surface from one

hole of the injector at different injection pressures for low and high injection temperatures, where piston surface temperature

and spray distance are $110^{\circ} \mathrm{C}$ and $50 \mathrm{~mm}$. With the increase in injection pressure, the spray becomes dense and its width

increases regardless of the injection temperature. This is attributed to the higher injection pressure causing a larger amount

of fuel to be discharged from the nozzle, and the higher velocity at the nozzle exit. Consequently better atomization and stronger interaction with the surrounding gas can be achieved, leading to the stronger radial dispersion. Besides, it is evident

that the intensity of impingement increases with injection pressure, and there are far more droplets rebounding from the piston surface than with the lower injection pressure. The rebound potentially reduces droplets adhering to the piston

mixing with air and its penetration, especially at conditions when flash boiling occurs. It is noted that the spray plumes 
Fig. 4 presents the effect of injection temperature on the single spray plume and its impingement on the piston surface at an injection pressure of $100 \mathrm{bar}$ and distance of $50 \mathrm{~mm}$, and a piston surface temperature of $110^{\circ} \mathrm{C}$. For the given ambient pressure of 1.0 bar, five injection temperatures from 25 to $140{ }^{\circ} \mathrm{C}$ have been investigated, and those above $36^{\circ} \mathrm{C}$ (the saturation temperature of $n$-pentane at $1 \mathrm{~atm}$ ) lead to flash boiling conditions. Obviously, it is a jet-like spray and it has an intense impact on the piston surface at $25^{\circ} \mathrm{C}$. A slight increase of injection temperature does not change the spray and its impact. However, a further increase in temperature starts to induce the flash boiling phenomena - the spray becomes dilute and wide with a large spray angle. Flash boiling significantly weakens the spray impinging on the piston surface at high superheats - fuel impingement cannot be observed at an injection temperature of $140^{\circ} \mathrm{C}$. This can be explained by the fact that high injection temperature greatly reduces the droplet diameter due to the faster evaporation rate under flash boiling conditions [38]. As a result, these smaller droplets experience a shorter lifetime and have less momentum to reach the piston surface. Therefore, for the single-hole nozzle, flash boiling can effectively reduce or eliminate the impingement of the fuel spray.

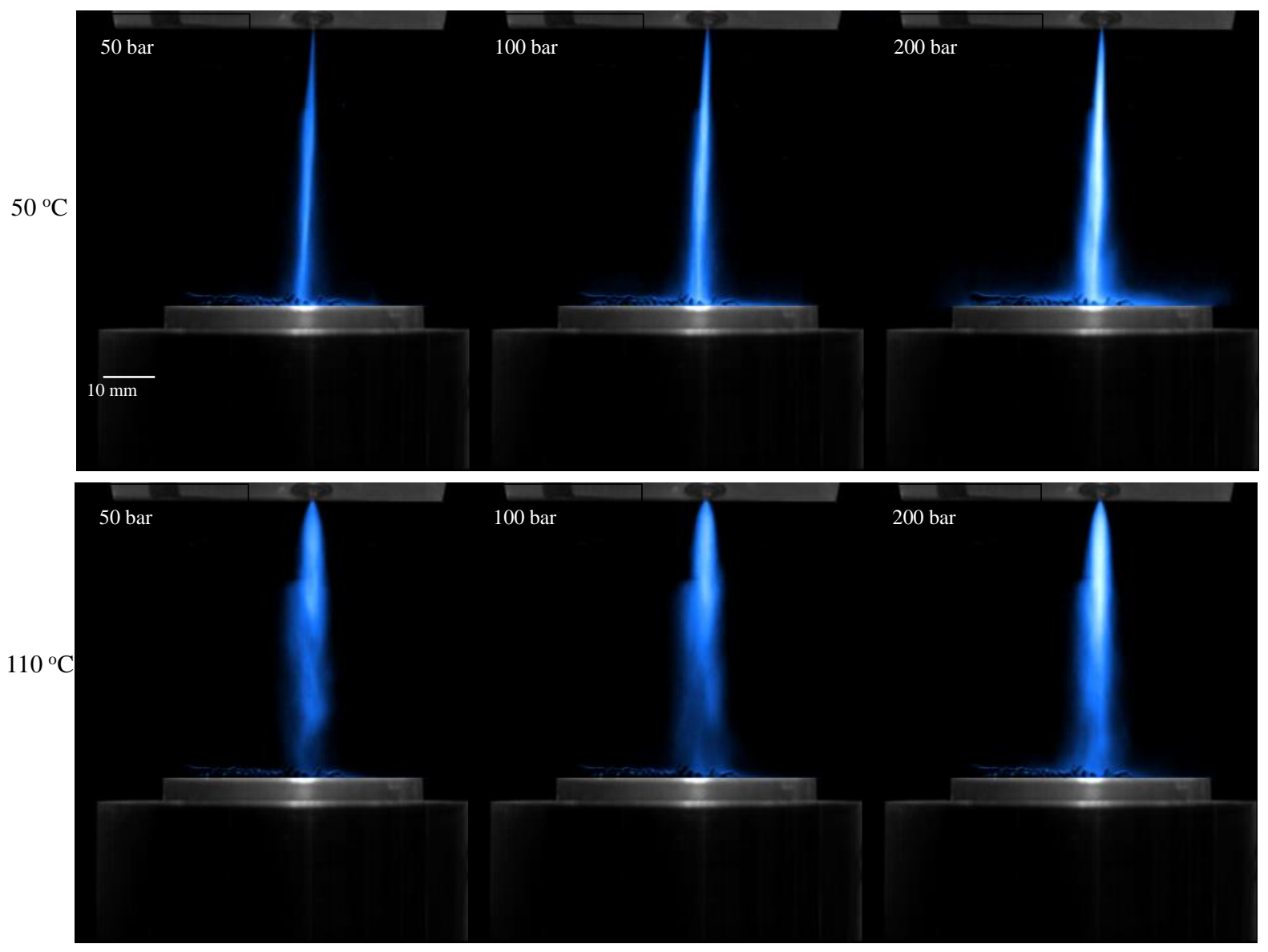


Fig. 3 Effect of injection pressure on spray and its impingement at conditions of injection temperatures of $50^{\circ} \mathrm{C}$ and $110^{\circ} \mathrm{C}$,

and piston surface temperature of $110^{\circ} \mathrm{C}$ for $\mathrm{n}$-pentane at ambient pressure

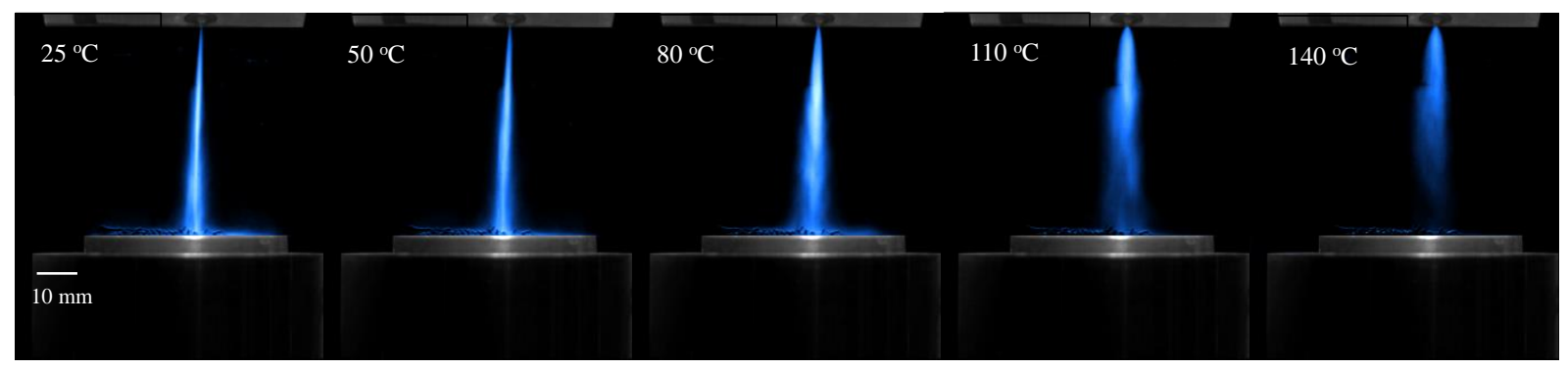

Fig. 4 Effect of injection temperature on spray and its impingement at injection pressure of 100 bar and piston surface

temperature of $110^{\circ} \mathrm{C}$ for n-pentane at ambient pressure

\subsection{Surface heat transfer dynamics}

Fig. 5 presents the temperature variations measured by the eight PRTs in response to a $2 \mathrm{~ms}$ injection with a pressure $\left(P_{\text {inj }}\right)$ of $100 \mathrm{bar}$, temperature $\left(T_{\mathrm{inj}}\right)$ of $50^{\circ} \mathrm{C}$, impact/injection distance $\left(D_{\text {inj }}\right)$ of $50 \mathrm{~mm}$ and a piston temperature $\left(T_{\text {pis }}\right)$ of $60^{\circ} \mathrm{C}$. It is noticed that temperatures measured by the $4^{\text {th }}, 5^{\text {th }}$ and $6^{\text {th }}$ PRTs located in the central region of the piston surface first show a quick reduction immediately after the fuel impacts upon the piston surface. Then they slowly recover to their initial temperature because of the wetting of the piston surface and evaporation of the liquid film. The other temperatures measured at the two sides have no obvious change, indicating that these regions are hardly influenced by the spray impingement. A similar trend is found after careful examination of various impingement cases at different conditions.

In the following discussion, only the $5^{\text {th }}$ PRT temperature is used as a typical one to investigate the effect of $T_{\text {pis }} T_{\text {inj }} P_{\text {inj }}$ and $D_{\text {inj }}$ on heat transfer behaviour on the piston surface, since the other TRDs show similar trends in the significant central region. 


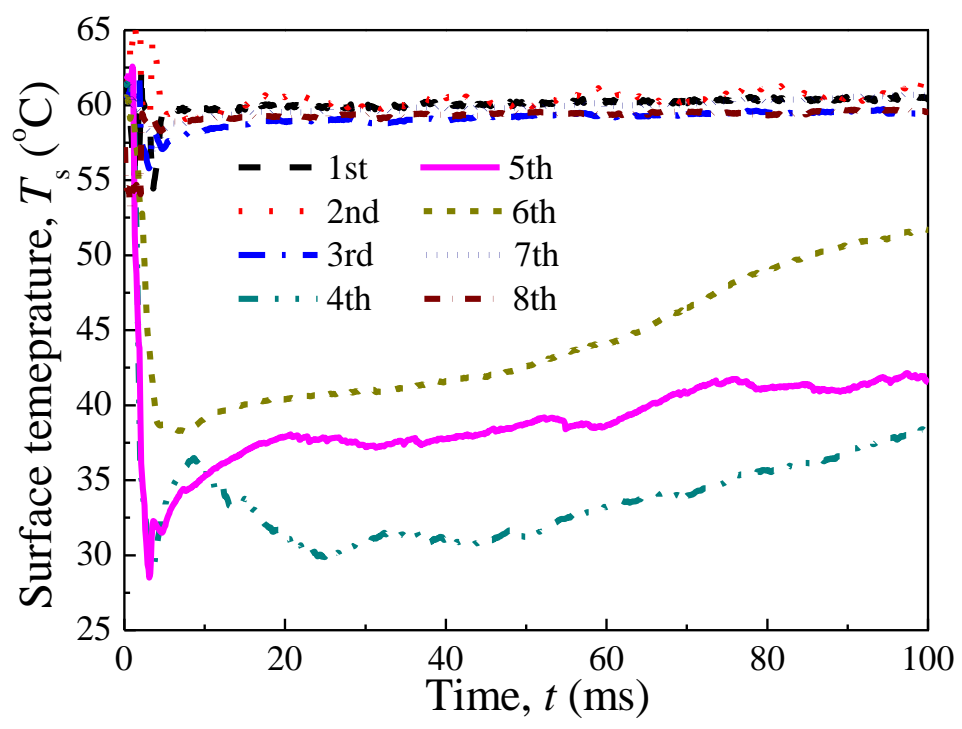

Fig. 5 Variation of surface temperature measured by the 1st to 8th PRTs with time at injection conditions of $P_{\text {inj }}=100$ bar,

$$
T_{\text {inj }}=50^{\circ} \mathrm{C}, D_{\text {inj }}=50 \mathrm{~mm}, T_{\text {pis }}=60^{\circ} \mathrm{C} \text {, for n-pentane at ambient pressure. }
$$

\section{1) Effect of piston temperature}

The effect of piston surface temperature on the variations of surface temperature reduction and heat flux as a function of time are shown in Fig. 6 and Fig. 7, at conditions of $P_{\text {inj }}=100$ bar, $T_{\text {inj }}=50^{\circ} \mathrm{C}$ and $D_{\text {inj }}=50 \mathrm{~mm}$. As seen from Fig. 6, all the surface temperatures $\left(T_{\mathrm{s}}\right)$ experience a quick decrease firstly once the droplets reach piston surface with the same rate, i.e. all the temperature curves during the fast drop period almost overlap. This fast decrease lasts about $2 \mathrm{~ms}$, the same as the injection duration. A minimum surface temperature $\left(T_{\mathrm{s}, \mathrm{min}}\right)$ is reached around the end of injection. A higher piston surface temperature results in a larger decrease of $T_{\mathrm{s}}$ and lower $T_{\mathrm{s}, \min }$ due to the more intense heat transfer caused by the larger temperature difference between the droplets $\left(T_{\mathrm{drop}}\right)$ and piston surface ( $\left.T_{\mathrm{pis}}\right)$. Afterwards, $T_{\mathrm{s}}$ starts to increase to its initial temperature at a far slower rate at the end of injection, except that it again experiences a second decrease after the previous slight increase at $T_{\text {inj }}$ of $110^{\circ} \mathrm{C}$. It is also observed that a higher $T_{\text {pis }}$ leads to larger increase rate during the recovery period; this is attributed to the higher evaporation rate and thus a short liquid film residence time on the piston surface.

Consequently, as shown in Fig. 7, all the surface heat fluxes $\left(q_{\mathrm{s}}\right)$ firstly rise quickly to their peak value $\left(q_{\mathrm{s}, \max }\right)$, then they also decline quickly in a very short time (about $1 \mathrm{~ms}$ ) after the end of injection. Thereafter, $q_{\mathrm{s}}$ gradually decreases until the complete evaporation of the liquid film. The first quick increase of $q_{\mathrm{s}}$ can be explained by the fact that the spray impingement leads to a strong convection on the piston surface with a high heat transfer coefficient $(h)$. However, during 
dominates the heat transfer between the liquid film and the piston with far lower $h$, compared to that in the strong initial convective heat transfer. It is noticed that higher $T_{\text {pis }}$ causes larger $q_{\mathrm{s} \text {, max }}$ due to the larger driving force, i.e. temperature difference between $T_{\text {drop }}$ and $T_{\text {pis. }}$ In addition, the liquid film has a far shorter lifetime on the piston surface with higher $T_{\text {pis }}(>$ $60^{\circ} \mathrm{C}$ ), which can probably be attributed to nucleate boiling occurring so more heat can be used to evaporate the liquid film.

Otherwise, only conduction between the liquid film and the piston surface governs heat transfer with a far smaller rate, concluded that piston surface temperature has a great influence on the heat transfer and liquid film residence time as fuel impinges onto the piston surface.

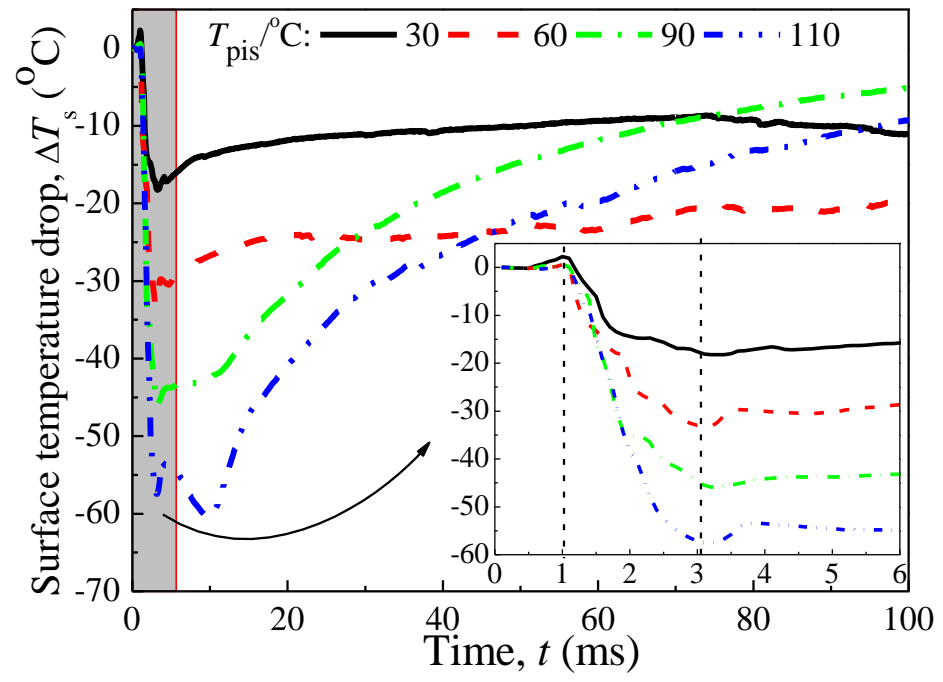

Fig. 6 Variation of the reduction of surface temperature $\left(T_{\mathrm{s}}\right)$ as a function of time at different piston temperature $\left(T_{\text {pis }}\right)$ with fuel impingement at conditions of $P_{\mathrm{inj}}=100 \mathrm{bar}, T_{\mathrm{inj}}=50^{\circ} \mathrm{C}$ and $D_{\mathrm{inj}}=50 \mathrm{~mm}$, for n-pentane at ambient pressure. 


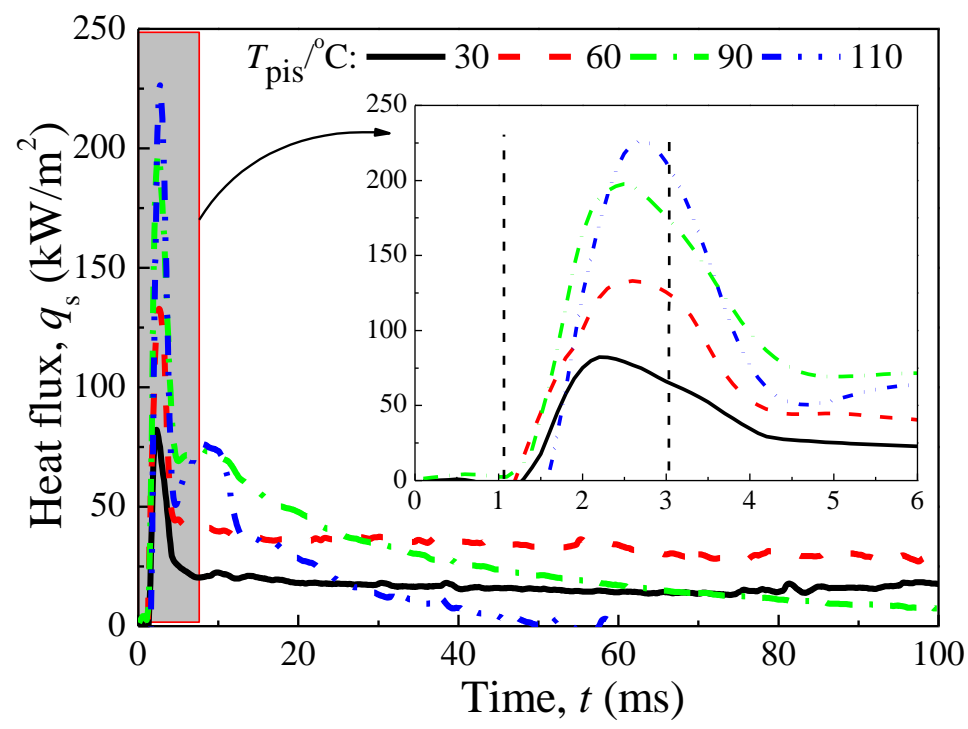

Fig. 7 Variation of heat flux $\left(q_{\mathrm{s}}\right)$ as a function of time at different piston temperature $\left(T_{\mathrm{pis}}\right)$ with fuel impingement at injection conditions of $P_{\mathrm{inj}}=100 \mathrm{bar}, T_{\mathrm{inj}}=50^{\circ} \mathrm{C}$ and $D_{\mathrm{inj}}=50 \mathrm{~mm}$, for n-pentane at ambient pressure.

2) Effect of injection pressure

Fig. 8 and Fig. 9 present the effect of injection pressure on the variations of surface temperature and heat flux as a

function of time at conditions of $T_{\text {pis }}=110^{\circ} \mathrm{C}, T_{\text {inj }}=50^{\circ} \mathrm{C}$ and $D_{\text {inj }}=50 \mathrm{~mm}$. It is found that fuel sprays under these injection

pressures all lead to impingement on the piston surface. A larger $P_{\text {inj }}$ brings lower $T_{\mathrm{s}}$, higher $q_{\mathrm{s}}$ and a shorter liquid lifetime.

This can be explained by considering aspects of heat transfer and the interaction between droplets and the wall surface.

Firstly, a larger injection pressure generates a higher droplet velocity, and consequently a stronger impingement takes place:

this enhances the heat transfer and reduces liquid film lifetime on the piston surface. Secondly, the droplets with a stronger impact upon the piston surface are more likely to splash rather than to adhere to its surface; this is seen in the impingement image shown in Fig. 3. Therefore, the amount of liquid film should be less than that with a lower injection pressure, which also reduces the liquid film lifetime. Thus, $P_{\mathrm{inj}}$ also greatly influences $T_{\mathrm{s}}, q_{\mathrm{s}}$ and the liquid film lifetime, and increasing $P_{\mathrm{inj}}$ could enhance heat transfer and reduce liquid residence time on the piston surface, if fuel impingement already happens. 


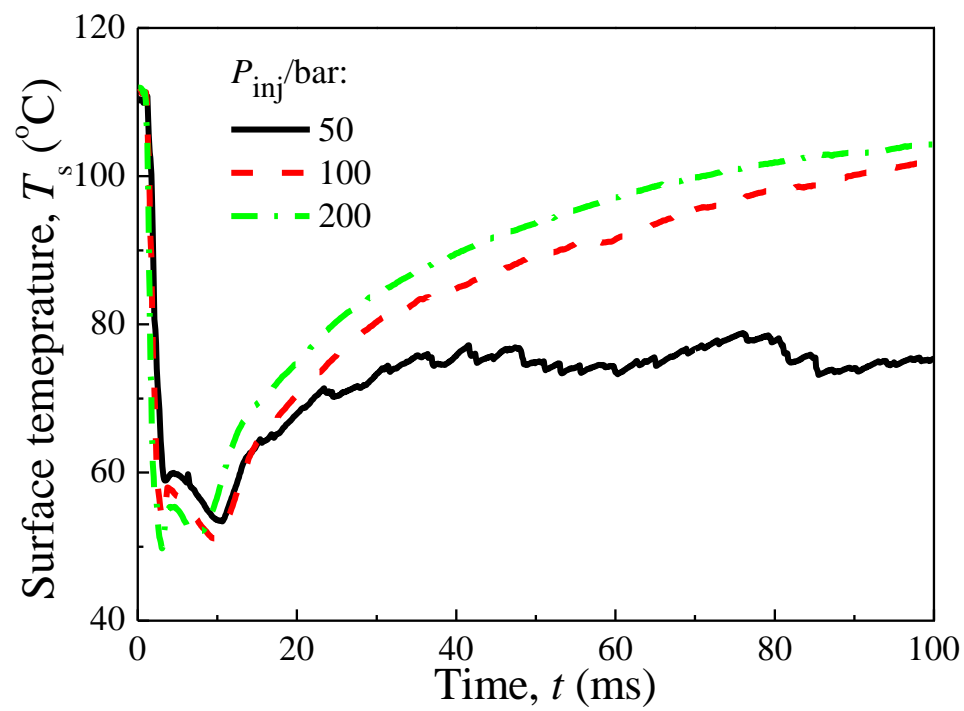

Fig. 8 Variation of surface temperature $\left(T_{\mathrm{s}}\right)$ as a function of time at different injection pressure $\left(P_{\mathrm{inj}}\right)$ with fuel impingement at injection conditions of $T_{\mathrm{pis}}=110^{\circ} \mathrm{C}, T_{\mathrm{inj}}=50^{\circ} \mathrm{C}$ and $D_{\mathrm{inj}}=50 \mathrm{~mm}$, for n-pentane at ambient pressure.

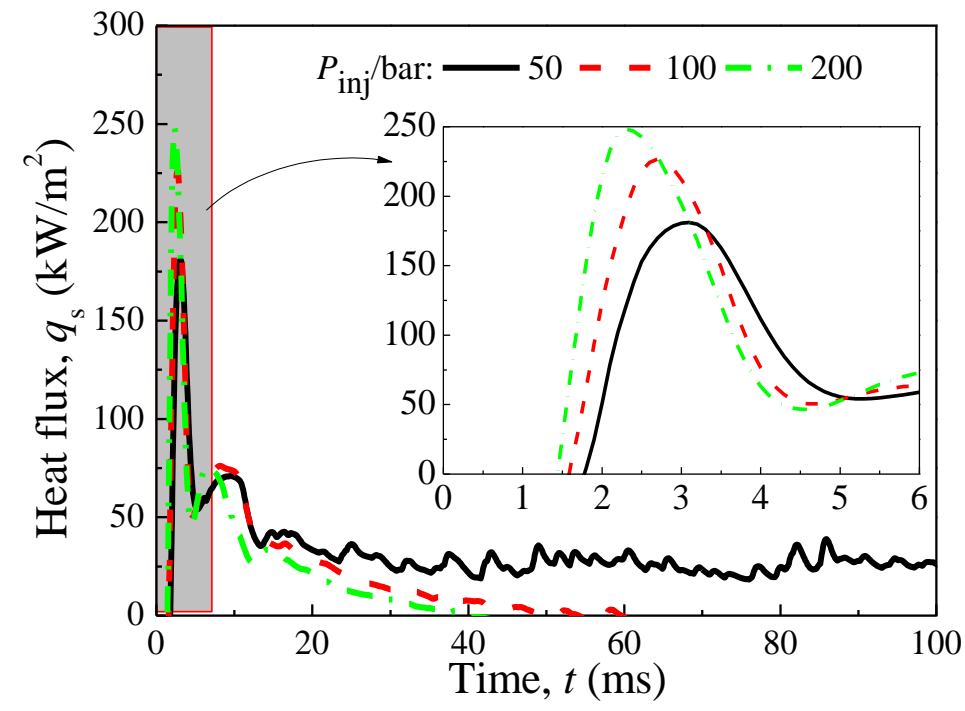

Fig. 9 Variation of heat flux $\left(q_{\mathrm{s}}\right)$ as a function of time at different injection pressure $\left(P_{\text {inj }}\right)$ with fuel impingement at injection conditions of $T_{\text {pis }}=110^{\circ} \mathrm{C}, T_{\mathrm{inj}}=50^{\circ} \mathrm{C}$ and $D_{\text {inj }}=50 \mathrm{~mm}$, for n-pentane at ambient pressure.

3) Effect of fuel injection temperature

Fig. 10 and Fig. 11 present the effect of injection temperature on the variations of surface temperature and heat flux as

a function of time at conditions of $P_{\mathrm{inj}}=100 \mathrm{bar}, T_{\mathrm{pis}}=110^{\circ} \mathrm{C}$ and $D_{\mathrm{inj}}=50 \mathrm{~mm}$. It is found that a lower $T_{\mathrm{inj}}$ causes larger a reduction of $T_{\mathrm{s}}$ and a higher $q_{\mathrm{s}}$, contributing to more intense cooling on the piston surface. However, a higher $q_{\mathrm{s}}$ does not help to reduce liquid film residence time, which is unlike its behaviour with injection pressure and piston temperature. At the same piston surface temperature, that is below the Leidenfrost point, and injection pressure, the factors affecting the 
cooling effect and liquid film deposition are: the droplet temperature $T_{\mathrm{d}}$, heat transfer coefficient $h$, and droplet density.

Firstly, a higher $T_{\text {inj }}$ should generate smaller temperature difference ( $\Delta T=T_{\text {pis }}-T_{\mathrm{d}}$ ), meaning a smaller driving force for heat transfer. Although $T_{\text {inj }}$ reaches or exceeds $T_{\text {pis }}$, the rapid reduction of $T_{\mathrm{s}}$ can be still observed as it increases to 110 and $140^{\circ} \mathrm{C}$, due to the fast evaporation of droplets before their impact on the piston surface. Secondly, according to the results shown in Fig. 4, droplets injected with a higher $T_{\text {inj }}$ undergo a faster evaporation rate and shorter lifetime. Thus, numerous droplets disappear during their flight, especially at the conditions of a very high superheat $\left(\Delta T_{\text {superheat }} \geq 74{ }^{\circ} \mathrm{C}\right)$, resulting in a much weaker impact and lower $h$. Thirdly, for a spray at the lower $T_{\mathrm{inj}}$, more droplets are deposited on the piston surface with a lower temperature, which is more likely to have more liquid film on the piston surface and experience a longer lifetime even though there is a higher $q_{\mathrm{s}}$. Therefore, a higher injection temperature is apparently beneficial to GDI engines by reducing fuel spray impingement and liquid film residence time on the piston surface for the single-hole injector nozzle.

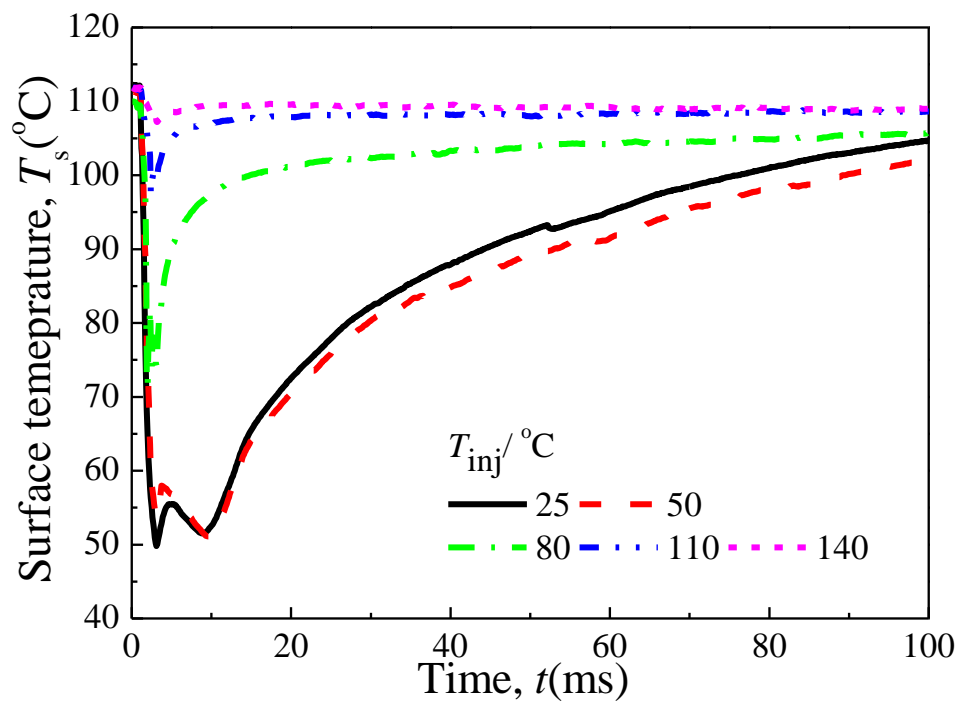

Fig. 10 Variation of surface temperature $\left(T_{\mathrm{s}}\right)$ as a function of time at different injection temperature $\left(T_{\mathrm{inj}}\right)$ with fuel impingement at conditions of $P_{\mathrm{inj}}=100 \mathrm{bar}, T_{\mathrm{pis}}=110^{\circ} \mathrm{C}$ and $D_{\mathrm{inj}}=50 \mathrm{~mm}$, for n-pentane at ambient pressure. 


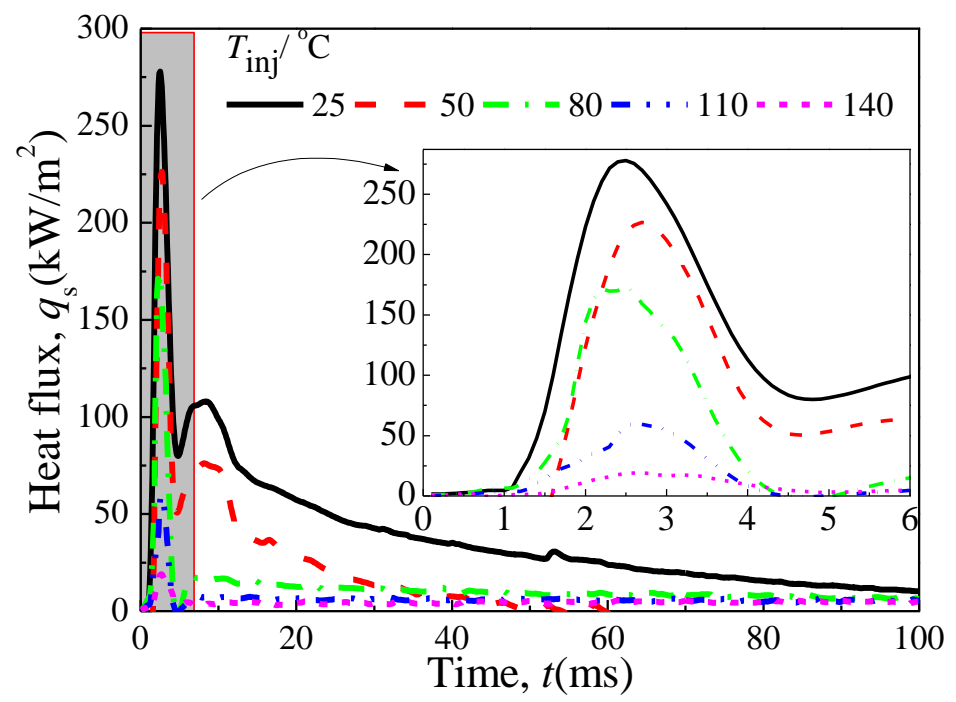

Fig. 11 Variation of heat flux $\left(q_{\mathrm{s}}\right)$ as a function of time at different injection temperature $\left(T_{\text {inj }}\right)$ with fuel impingement at conditions of $P_{\text {inj }}=100$ bar, $T_{\text {pis }}=110^{\circ} \mathrm{C}$ and $D_{\text {inj }}=50 \mathrm{~mm}$, for n-pentane at ambient pressure.

The effect of two injection distances $(50$ and $70 \mathrm{~mm}$ ) on the surface temperature and heat flux with time are shown in

Fig. 12 and Fig. 13, at conditions of $P_{\text {inj }}=100$ bar, $T_{\text {pis }}=110^{\circ} \mathrm{C}$ and $T_{\text {inj }}=50^{\circ} \mathrm{C}$. Different injection distances correspond to fuel injected at different time points in GDI engines. A larger injection distance $D_{\text {inj }}$ can reduce the reduction of $T_{\mathrm{s}}$, as a result, it causes lower $q_{\mathrm{s}}$ and a weak cooling effect on the piston surface. This is reasonable as the fuel droplets have less momentum, i.e. lower velocity and smaller size, after the longer flight distance and more time for evaporation. On the other hand, larger $D_{\text {inj }}$ leads to longer liquid film residence time, because the droplets are more likely to adhere to the piston surface due to the weaker impact compared to the shorter $D_{\text {inj. }}$ It should be noted that in GDI engines the behaviour is more complex because the injection in-cylinder pressure also varies due to the piston motion. 


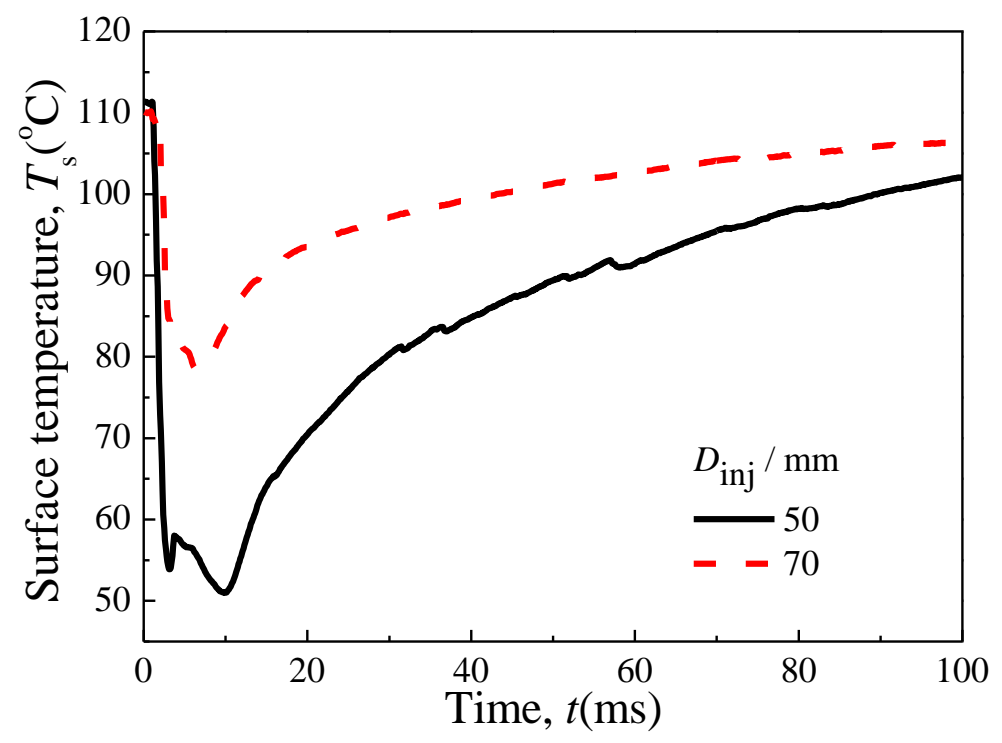

Fig. 12 Variation of surface temperature $\left(T_{\mathrm{s}}\right)$ as a function of time at different injector distances with fuel impingement at injection conditions of $P_{\text {inj }}=100 \mathrm{bar}, T_{\mathrm{pis}}=110^{\circ} \mathrm{C}$ and $T_{\mathrm{inj}}=50^{\circ} \mathrm{C}$, for n-pentane at ambient pressure.

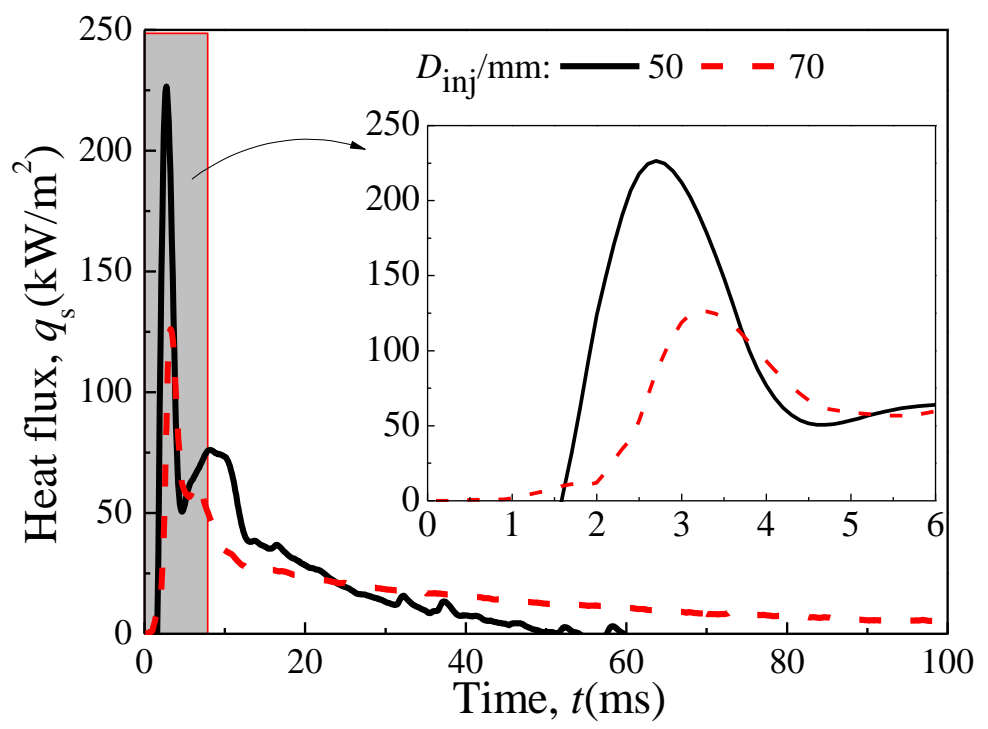

Fig. 13 Variation of heat flux $\left(q_{\mathrm{s}}\right)$ as a function of time at different injector distances with fuel impingement at injection conditions of $P_{\mathrm{inj}}=100 \mathrm{bar}, T_{\mathrm{pis}}=110^{\circ} \mathrm{C}$ and $T_{\mathrm{inj}}=50^{\circ} \mathrm{C}$, for n-pentane at ambient pressure.

5) Normalization of the heat fluxes at various experimental conditions

From the above results, all the heat flux curves are strongly time-varying before the start of their relatively stable

period of liquid film evaporation. They first increase rapidly to a peak value and then decrease almost as rapidly (in a few milliseconds). Usually, the peak value $\left(q_{\mathrm{s}, \max }\right)$ and the time at this point $\left(t_{\max }\right)$ are considered as important factors to characterize the transient heat transfer [39-41]. Table 1 lists all the values of $q_{\mathrm{s}, \max }$ and $t_{\max }$ at various experimental 
316 and $T_{\text {inj, }}$, as shown in Fig. 14, although two curves have opposite trends. Two empirical correlations can be used to describe

317 these two linear variations, as given in Equations (11) and (12).

$$
\begin{aligned}
& q_{\mathrm{s}, \text { max }}=342-2.36 T_{\mathrm{inj}} \\
& q_{\mathrm{s}, \max }=25.6+1.85 T_{\mathrm{pis}}
\end{aligned}
$$

\begin{tabular}{|c|c|c|c|c|c|c|}
\hline Exp. Cases & $T_{\mathrm{inj}} /{ }^{\circ} \mathrm{C}$ & $P_{\text {inj }} /$ bar & $T_{\mathrm{pis}} /{ }^{\circ} \mathrm{C}$ & $D_{\text {inj }} / \mathrm{mm}$ & $q_{\mathrm{s}, \max } / \mathrm{kW} \cdot \mathrm{m}^{-2}$ & $t_{\max } / \mathrm{ms}$ \\
\hline 1 & 50 & 100 & 30 & 50 & 82.1 & 2.3 \\
\hline 2 & 50 & 100 & 60 & 50 & 133 & 2.7 \\
\hline 3 & 50 & 100 & 90 & 50 & 198 & 2.5 \\
\hline 4 & 50 & 100 & 110 & 50 & 227 & 2.7 \\
\hline 5 & 50 & 50 & 110 & 50 & 181 & 3.1 \\
\hline 4 & 50 & 100 & 110 & 50 & 227 & 2.7 \\
\hline 6 & 50 & 200 & 110 & 50 & 248 & 2.3 \\
\hline 7 & 25 & 100 & 110 & 50 & 278 & 2.5 \\
\hline 4 & 50 & 100 & 110 & 50 & 227 & 2.7 \\
\hline 8 & 80 & 100 & 110 & 50 & 173 & 2.5 \\
\hline 9 & 110 & 100 & 110 & 50 & 59.9 & 2.6 \\
\hline 10 & 140 & 100 & 110 & 50 & 19.1 & 2.6 \\
\hline 4 & 50 & 100 & 110 & 50 & 227 & 2.7 \\
\hline 11 & 50 & 100 & 110 & 70 & 126 & 3.3 \\
\hline
\end{tabular}

Table 1 Values of the maximum heat flux and the time of its occurrence for various experimental conditions 


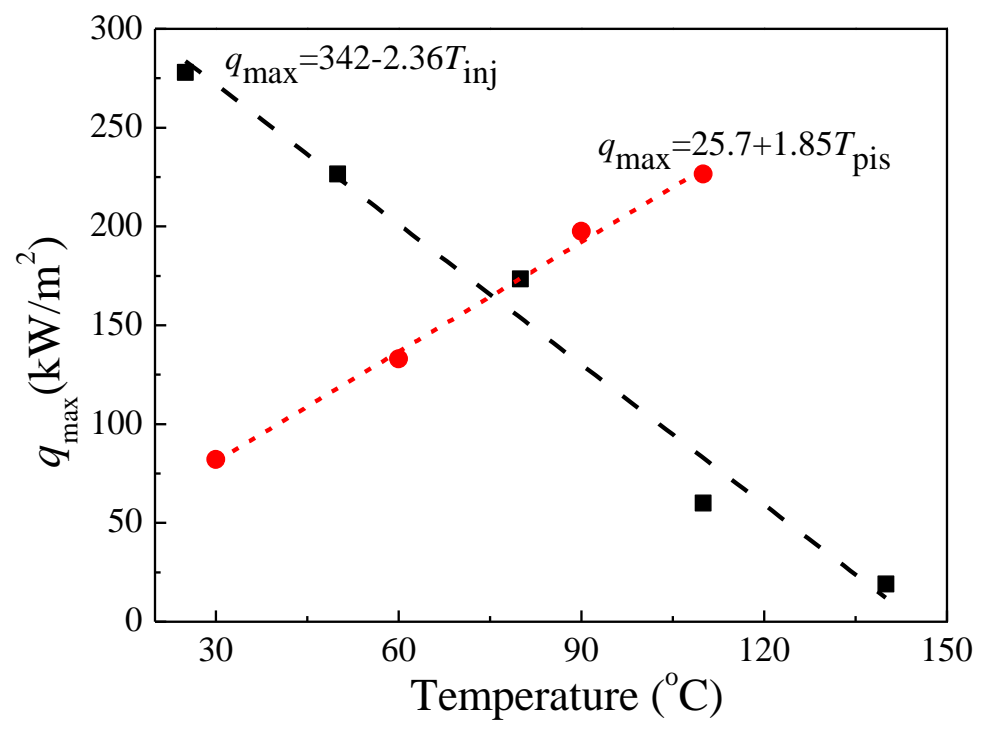

Fig. 14 Variations of $q_{\max }$ with $T_{\text {inj }}$ and $T_{\text {pis }}$ at injection pressure of 100 bar and distance of $50 \mathrm{~mm}$

If we introduce the spray Biot number $\left(B i^{*}\right)$ and Fourier number $\left(\mathrm{Fo}_{\mathrm{s}}\right)$ as already used in transient spray cooling, and given in Equations (13) and (14), then the heat flux curve can be normalized in terms of $B i^{*} / B i^{*}{ }_{\text {max }}$ versus $F o_{\mathrm{s}} / F o_{\mathrm{s}, \text { max }}$, as shown in Fig. 15,

$$
\begin{aligned}
& B i^{*}=\frac{h^{*} \delta}{\lambda_{s}}=\frac{q \delta}{\left(T_{s}-T_{d}\right) \lambda_{s}} \\
& F o_{s}=\frac{\alpha t}{\delta^{2}}
\end{aligned}
$$

Where: $\delta, \lambda_{\mathrm{s}}, \alpha$ are the length scale, heat conductivity coefficient and thermal diffusivity coefficient of the substrate.

Fig. 15 shows that all the non-dimensional curves show high similarity when $F o_{\mathrm{s}} / F o_{\mathrm{s}}$, max is less than 2, regardless of injection conditions. Afterwards, deviation emerges among them but still with the same variation trend during the liquid film evaporation stage. Also, a general correlation can be found for the fast cooling stage. as given in Equation (15).

$$
\frac{B i^{*}}{B i_{\text {max }}^{*}}= \begin{cases}-1.29+2.29 \frac{F O_{s}}{F o_{s, \text { max }}} & 0.5<\frac{F O_{s}}{F o_{s, \text { max }}} \leq 1 \\ 1.87-0.87 \frac{F O_{s}}{F o_{s, \text { max }}} & 1<\frac{F O_{s}}{F o_{s, \text { max }}} \leq 2\end{cases}
$$




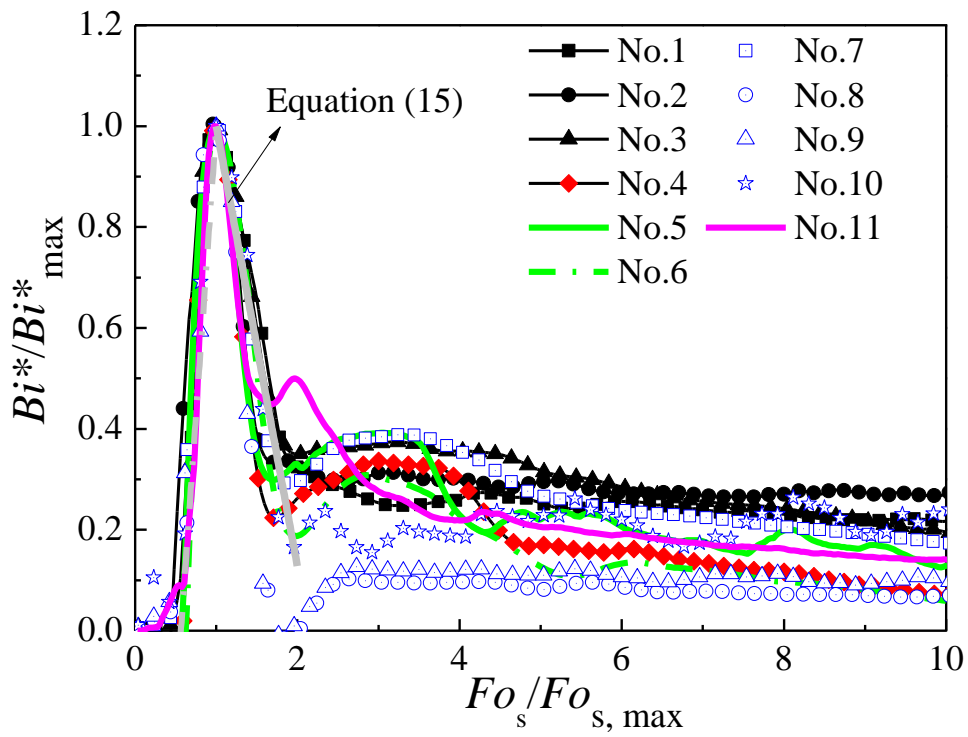

Fig. 15 Non-dimensional heat flux versus dimensionless time

surface has been conducted to explore the effects of different injection conditions on the: surface temperature, heat flux and liquid film residence time. The main finding can be summarized as follows.

1) An increase in piston temperature results in an increase in the surface temperature reduction and heat flux peak, leading to stronger heat transfer and a higher evaporation rate, due to the larger heat transfer driving force. Thus, the liquid film lifetime on the piston surface can be greatly reduced.

2) Increasing the injection pressure and decreasing the impact distance enhance heat transfer and impact intensities with larger heat flux peak due to a higher heat transfer coefficient and droplet momentum. The liquid film residence time is also reduced because more droplets rebound rather than adhere to the piston surface.

3) The injection temperature significantly affects spray atomization and its later impact on the piston surface. Higher injection temperatures greatly improve the atomization and reduce the intensity of impact especially, with flash boiling atomization, leading to less surface temperature reduction and lower heat flux, as well as less liquid film being deposited on the piston surface and consequently a shorter liquid film residence time.

4) The peak heat flux shows a linear variation with injection and piston temperatures. The dimensionless curves of heat flux in terms of Biot $\left(B i^{*}\right)$ and Fourier $\left(F_{\mathrm{s}}\right)$ numbers are highly similar at the first rapid cooling stage, and a general 


\section{Acknowledgement}

This work was partially supported by the Natural Science Foundation of China (51406151). Great appreciation is given

to the Osney Thermo-fluids Laboratory in the University of Oxford for providing the fast-response thin film Platinum

\section{Nomenclature}

\begin{tabular}{|c|c|c|c|}
\hline$B i^{*}$ & Biot number & $X$ & sensitiity matrix \\
\hline$c$ & specific heat capacity $(\mathrm{J} /(\mathrm{kg} \cdot \mathrm{K}))$ & $y$ & Spatial coordinate $(\mathrm{m})$ \\
\hline$D$ & impinge distance $(\mathrm{m})$ & $Y$ & measured temperature $(\mathrm{K})$ \\
\hline$f$ & filter coefficient & & \\
\hline$F$ & filter matrix & \multicolumn{2}{|c|}{ Greek symbols } \\
\hline $\mathrm{Fo}_{s}$ & Fourier number & $\alpha$ & thermal diffusivity $(\mathrm{m} 2 / \mathrm{s})$ \\
\hline$h$ & heat transfer coefficient & $\rho$ & density $\left(\mathrm{kg} / \mathrm{m}^{3}\right)$ \\
\hline$H$ & $\begin{array}{l}\text { temperature measurement location or height of } \\
\text { piston }(\mathrm{m})\end{array}$ & $\lambda$ & thermal conductivity $(\mathrm{W} /(\mathrm{m} \cdot \mathrm{K}))$ \\
\hline$H_{t}$ & temporal first order regularization matrix & & \\
\hline$H_{s}$ & spatial first order regularization matrix & \multicolumn{2}{|c|}{ Subscripts } \\
\hline$I$ & number of heat flux & $c$ & position of temperature measurement \\
\hline$J$ & number of layer & $i$ & heat flux index \\
\hline$m$ & number of non-negligible filter coefficient & inj & injection \\
\hline$N$ & number of time step & $j$ & layer index \\
\hline$P$ & Pressure (bar) & $\max$ & maximum \\
\hline$q$ & heat flux $\left(\mathrm{W} / \mathrm{m}^{2}\right)$ & pis & piston \\
\hline$t$ & time $(\mathrm{s})$ & $s$ & surface \\
\hline$x$ & Spatial coordinate $(\mathrm{m})$ & 0 & initial state \\
\hline
\end{tabular}

\section{References}

[1] A.L.N. Moreira, A.S. Moita, M.R. Panão, Advances and challenges in explaining fuel spray impingement: How much of 
[3] B. Mohan, W. Yang, S.k. Chou, Fuel injection strategies for performance improvement and emissions reduction in compression ignition engines-A review, Renewable and Sustainable Energy Reviews, 28 (2013) 664-676.

[4] Q. Tang, H. Liu, M. Li, M. Yao, Optical study of spray-wall impingement impact on early-injection gasoline partially premixed combustion at low engine load, Applied Energy, 185 (2017) 708-719.

[5] F. Köpple, D. Seboldt, P. Jochmann, A. Hettinger, A. Kufferath, M. Bargende, Experimental Investigation of Fuel Impingement and Spray-Cooling on the Piston of a GDI Engine via Instantaneous Surface Temperature Measurements, SAE International Journal of Engines, 7 (2014) 1178-1194.

[6] P. Wang, R. Liang, Y. Yu, J. Zhang, J. Lv, M. Bai, The flow and heat transfer characteristics of engine oil inside the piston cooling gallery, Applied Thermal Engineering, 115 (2017) 620-629.

[7] X. Wang, P. Price, C.R. Stone, D. Richardson, Heat release and heat flux in a spray-guided direct-injection gasoline engine, Proceedings of the Institution of Mechanical Engineers, Part D: Journal of Automobile Engineering, 221 (2007) $1441-1452$.

[8] S.H. Bang, C.S. Lee, Application of background oriented Schlieren (BOS) method for visualization of evaporating impinged spray, Optik - International Journal for Light and Electron Optics, 126 (2015) 1606-1609.

[9] Y. Pei, J. Qin, X. Li, D. Zhang, K. Wang, Y. Liu, Experimental investigation on free and impingement spray fueled with n-butanol/diesel blended fuels, Fuel, 182 (2016) 248-258.

[11] M. Zhang, M. Xu, Y. Zhang, W. Zeng, Flow Field Characterization of Superheated Sprays from a Multi-Hole Injector

by Using High-Speed PIV, 1 (2012).

[12] A. Montanaro, L. Allocca, M. Costa, U. Sorge, Assessment of a 3D CFD model for GDI spray impact against wall through experiments based on different optical techniques, International Journal of Multiphase Flow, 84 (2016) 204-216.

[13] Z. Wang, H. Guo, C. Wang, H. Xu, Y. Li, Microscopic level study on the spray impingement process and characteristics, 
Applied Energy, 197 (2017) 114-123.

[14] Z.-F. Zhou, G.-Y. Lu, B. Chen, Numerical study on the spray and thermal characteristics of R404A flashing spray using

OpenFOAM, International Journal of Heat and Mass Transfer, 117 (2018) 1312-1321.

[15] J. Serras-Pereira, P.G. Aleiferis, H.L. Walmsley, T.J. Davies, R.F. Cracknell, Heat flux characteristics of spray wall

impingement with ethanol, butanol, iso-octane, gasoline and E10 fuels, International Journal of Heat and Fluid Flow, 44 (2013) 662-683.

[16] J. Serras-Pereira, P.G. Aleiferis, D. Richardson, Imaging and heat flux measurements of wall impinging sprays of hydrocarbons and alcohols in a direct-injection spark-ignition engine, Fuel, 91 (2012) 264-297.

[18] F. Schulz, J. Schmidt, A. Kufferath, W. Samenfink, Gasoline Wall Films and Spray/Wall Interaction Analyzed by

Infrared Thermography, SAE International Journal of Engines, 7 (2014) 1165-1177.

[19] C. Arcoumanis, P. Cutter, D.S. Whitelaw, Heat Transfer Processes in Diesel Engines, Chemical Engineering Research and Design, 76 (1998) 124-132.

[20] C. Arcoumanis, J.C. Chang, Heat transfer between a heated plate and an impinging transient diesel spray, Experiments 403 in Fluids, $16(1993)$ 105-119.

[24] A. Montanaro, L. Allocca, M. Lazzaro, G. Meccariello, Impinging Jets of Fuel on a Heated Surface: Effects of Wall 

review, International Journal of Engine Research, 2 (2001) 119-148.

[26] J. Serras-Pereira, Z.V. Romunde, P.G. Aleiferis, D. Richardson, S. Wallace, R.F. Cracknell, Cavitation, primary break-up and flash boiling of gasoline, -octane and -pentane with a real-size optical direct-injection nozzle, Fuel, 89 (2010) 2592-2607.

[27] Serras-Pereira, Aleiferis, Richardson, Spray Development, Flow Interactions and Wall Impingement in a Direct-Injection Spark-Ignition Engine, Journal of Avian Biology, 85 (2007) 170-176.

[28] S.H. Mohd Murad, J. Camm, M. Davy, R. Stone, D. Richardson, Spray Behaviour and Particulate Matter Emissions with M15 Methanol/Gasoline Blends in a GDI Engine, 1 (2016).

[29] E. Piccini, S. Guo, T. Jones, The development of a new direct-heat-flux gauge for heat-transfer facilities, Measurement Science and Technology, 11 (2000) 342.

[30] J.V. Beck, K.A. Woodbury, Inverse heat conduction problem: Sensitivity coefficient insights, filter coefficients, and intrinsic verification, International Journal of Heat \& Mass Transfer, 97 (2016) 578-588.

[31] K.A. Woodbury, J.V. Beck, Estimation metrics and optimal regularization in a Tikhonov digital filter for the inverse heat conduction problem, International Journal of Heat \& Mass Transfer, 62 (2013) 31-39.

[32] H. Najafi, K.A. Woodbury, J.V. Beck, A filter based solution for inverse heat conduction problems in multi-layer mediums, International Journal of Heat \& Mass Transfer, 83 (2015) 710-720.

[33] J.-m. Tian, B. Chen, Z.-f. Zhou, Methodology of surface heat flux estimation for 2D multi-layer mediums, International Journal of Heat and Mass Transfer, 114 (2017) 675-687.

[34] Z.F. Zhou, T.Y. Xu, B. Chen, Algorithms for the estimation of transient surface heat flux during ultra-fast surface cooling, International Journal of Heat \& Mass Transfer, 100 (2016) 1-10.

[35] H. Guo, X. Ma, Y. Li, S. Liang, Z. Wang, H. Xu, J. Wang, Effect of flash boiling on microscopic and macroscopic spray characteristics in optical GDI engine, Fuel, 190 (2017) 79-89.

[36] W. Zeng, M. Xu, G. Zhang, Y. Zhang, D.J. Cleary, Atomization and vaporization for flash-boiling multi-hole sprays 
with alcohol fuels, Fuel, 95 (2012) 287-297.

437 [37] Y. Li, H. Guo, X. Ma, Y. Qi, Z. Wang, H. Xu, S. Shuai, Morphology analysis on multi-jet flash-boiling sprays under 438 wide ambient pressures, Fuel, 211 (2018) 38-47.

[38] Z. Chen, A. Yao, C. Yao, Z. Yin, H. Xu, P. Geng, Z. Dou, J. Hu, T. Wu, M. Ma, Effect of fuel temperature on the 440 methanol spray and nozzle internal flow, Applied Thermal Engineering, 114 (2017) 673-684.

441 [39] J.M. Tian, B. Chen, D. Li, Z.F. Zhou, Transient spray cooling: Similarity of dynamic heat flux for different cryogens, 442 nozzles and substrates, International Journal of Heat \& Mass Transfer, 108 (2017) 561-571.

[40] Z.-f. Zhou, B. Chen, R. Wang, F.-1. Bai, G.-x. Wang, Coupling effect of hypobaric pressure and spray distance on heat 444 transfer dynamics of R134a pulsed flashing spray cooling, Experimental Thermal and Fluid Science, 70 (2016) 96-104.

445 [41] Z.-F. Zhou, R. Wang, B. Chen, T. Yang, G.-X. Wang, Heat transfer characteristics during pulsed spray cooling with 446 R404A at different spray distances and back pressures, Applied Thermal Engineering, 102 (2016) 813-821. 